\title{
The Role of Amino Acid Composition in the Charge Inversion of Deprotonated Peptides via Gas-Phase Ion/Ion Reactions
}

\author{
Joshua F. Emory and Scott A. McLuckey \\ Department of Chemistry, Purdue University, West Lafayette, Indiana, USA
}

Ion/ion charge inversion via multiple proton transfer reactions occurs via a long-lived intermediate. The intermediate can be observed if its lifetime is long relative to mechanisms for removal of excess energy (i.e., emission and collisional stabilization). The likelihood for formation of a stabilized intermediate is a function of characteristics of the reagent and analyte ions. This work is focused on the role acidic and basic sites of a deprotonated peptide play in the formation of a stabilized intermediate upon charge inversion with multiply protonated polypropyleniminediaminobutane dendrimers. A group of model peptides based on leucine enkephalin was used, which included YGGFL, YGGFLF, YGGFLK, YGGFLR and YGGFLH as well as methyl esterified and acetylated versions. Results showed that peptides containing basic amino acid residues charge inverted primarily by proton transfer from the DAB dendrimer to the peptide, whereas peptides without basic amino acids charge inverted primarily by complex formation with the $\mathrm{DAB}$ dendrimer. The modified versions of the peptides highlighted the importance of the presence of the C-terminus as well as the basicity of the peptide in the observation of a stabilized intermediate. These results provide new insights into the nature of the interactions that occur in the charge inversion of polypeptide anions via ion/ion reactions. (J Am Soc Mass Spectrom 2009, 20, 180-187) () 2009 Published by Elsevier Inc. on behalf of American Society for Mass Spectrometry

$\mathrm{T}$ andem mass spectrometry is commonly used to derive sequence information from protein and peptide ions. The quality and extent of the sequence information obtained using a tandem mass spectrometry experiment are dependent upon the nature of the ion (e.g., even-electron versus odd-electron, polarity and magnitude of charge, etc.) and the conditions used to induce dissociation. In general, the nature of the ion is defined by the ionization method. However, gas-phase ion/ion reactions provide a means for transforming one ion type into another and thereby allow for a decoupling of the ion type formed initially by the ionization method and the nature of the ion subjected to ion activation. One such ion transformation is charge inversion, whereby ions initially formed in one polarity are converted to ions of the opposite polarity [1-3]. Unlike highly endothermic charge inversion reactions involving electronic transitions that can be induced via high-energy collisions [4-7], ion/ion charge inversion is a highly exothermic process that occurs via multiple ion transfers in a single collision. Efficiencies about $10 \%$ can therefore be obtained with the ion/ion reaction approach without the need for high accelerating voltages, provided the chemistry for multiple

Address reprint requests to Dr. S. A. McLuckey, Department of Chemistry, Purdue University, 1393 Brown Laboratories, West Lafayette, IN 479071393, USA. E-mail: mcluckey@purdue.edu ion transfers is favorable [1, 2]. Furthermore, the electronic transitions associated with the high-energy collision approach are vertical and often lead to the population of excited states and subsequent fragmentation of the analyte ions. No analyte ion fragmentation has yet been observed with ion/ion charge inversion. Ion/ion charge inversion is one of a larger class of approaches for manipulating the charge states of macro-ions. Methods for altering charge states of ions formed via electrospray ionization (ESI) [8] include the manipulation of solution conditions [9], and the use of either ion/molecule [10-13] or ion/ion chemistry [14-19] to reduce ion charge in the gas-phase. Ion/ion reactions have proven to be particularly effective in manipulating charge states due to their high exothermicities and large reaction cross-sections [20]. Charge state reduction, either before sampling ions into a mass spectrometer or within an ion trap, has been demonstrated to be useful in a number of applications such as the simplification of ESI mass spectra of mixtures [18-21]. Ion/ion charge state reduction in ion traps has also been demonstrated to simplify product ion spectra derived from multiply charged ions [5-7, 22, 23 and to concentrate ions into a single charge state [24]. Singly charged reagent ions are well-suited to reducing analyte ion charge states within a single polarity manifold but are not well-suited for charge inversion because the analyte must go through the
(C) 2009 Published by Elsevier Inc. on behalf of American Society for Mass Spectrometry. 1044-0305/09/\$32.00

doi:10.1016/j.jasms.2008.08.015
Published online September 5, 2008 Received June 27, 2008 Revised August 23, 2008 Accepted August 26, 2008 
neutral state. Due to the limited time that a neutral species remains in the reaction volume, the relatively low ion and analyte neutral densities, and the lower cross-sections associated with ion/molecule reactions, the likelihood is very low that a neutralized analyte will be subsequently ionized by the reagent ions. Charge inversion is much more likely to occur if two or more charge-transfer reactions occur in a single ion/ion encounter. Multiple charge transfers are most likely to occur via the formation of a relatively long-lived complex; as depicted for the charge inversion of a singly deprotonated analyte, $\mathrm{M}$, to form a singly protonated analyte via reaction with a multiply protonated reagent, $X$ :

$$
\begin{aligned}
(\mathrm{M} & -\mathrm{H})^{-}+(\mathrm{X}+\mathrm{mH})^{\mathrm{m}+} \\
& \rightarrow[(\mathrm{M}+\mathrm{X}+(\mathrm{m}-1) \mathrm{H})]^{(\mathrm{m}-1)+*} \\
& \rightarrow(\mathrm{M}+\mathrm{H})^{n+}+(\mathrm{X}+(\mathrm{m}-\mathrm{n}-1) \mathrm{H})^{(\mathrm{m}-\mathrm{n}-1)+}
\end{aligned}
$$

Previous work with deprotonated bradykinin and anions of model peptides of sequence GAILXGAILR and KGAILXGAILR, where $X=$ the amino acids $\mathrm{D} / \mathrm{K} / \mathrm{P}$, have shown that the nature and charge state of the reagent can play a major role in the extent to which the intermediate species breaks up into multiple proton transfer products versus the extent to which the stabilized intermediate, $[(M+X+(n-1) H)]^{(n-1)+}$, is observed [25]. For example, when multiply protonated insulin was used as the charge inversion reagent, significant adduct formation was observed (i.e., the stabilized intermediate was formed). Multiply protonated polypropyleniminediaminobutane dendrimers, on the other hand, showed no propensity for adduct formation with bradykinin or any of the other model peptides. All of the model peptides, however, contained at least one basic amino acid residue. In this work, we examine the role of peptide composition in the competition between charge inversion via adduct formation versus proton transfer for cases in which a basic amino acid is not present in the peptide using dendrimers as the charge inversion reagents.

\section{Experimental}

\section{Materials}

Methanol, ammonium hydroxide, and glacial acetic acid were purchased from Mallinckrodt (Phillipsburg, NJ). The peptides YGGFL, YGGFLK, YGGFLR, and the polypropylenimine-diaminobutane (DAB) dendrimers were purchased from Sigma Aldrich (St. Louis, MO). Custom peptides YGGFLF, YGGFLH, YGGHFL, and YGGKFL were purchased from CPC Scientific (San Jose, CA). Procedures for peptide modifications (acetylation and methyl esterification) are included in the Supplementary Information section, which can be found in the electronic version of this article. Primary amine functionalized DAB generations 4 and 5 were each electro- sprayed from an aqueous $\sim 2 \%$ acetic acid solution that had a dendrimer concentration between $\sim 1 \%$ and $2 \%$ by weight (see Supplementary Figure 1). Negatively charged peptide ions were formed by nanospray from a $50 / 50$ (vol/vol) water/methanol solution that contained $2 \%$ to $5 \%$ ammonium hydroxide and had a peptide concentration of $10-20 \mu \mathrm{M}$.

\section{Apparatus}

All experiments were performed using a modified version of a 4000 QTRAP (Applied Biosystems/MDS SCIEX, Concord, ON, Canada) that had been modified for mutual storage ion/ion reactions. The instrument is composed of four quadrupole arrays arranged in series, which are referred to as Q0-Q3. The 4000 QTRAP was modified to allow for mutual storage ion/ion reactions in the first quadrupole Q0, the third quadrupole (collision cell) Q2, and/or the fourth quadrupole (mass analyzer) Q3 by allowing for the application of auxiliary $\mathrm{RF}$ to the end lenses of Q2 and Q3 and to the end lens of Q0. Additionally, all three quadrupoles (Q0, Q2, and Q3) were equipped to allow for the application of an auxiliary RF voltage in dipolar fashion to one of the pairs of opposing rods in each of the arrays. Finally, a homebuilt system allowed independent triggering of up to three nanospray sources for the introduction of positive and negative ions into the mass spectrometer [26]. All experiments were controlled by a research version of MS Expo software version 3.7 provided by MDS SCIEX.

For ion/ion reaction experiments, the positive highvoltage power supply for the nanospray source of DAB dendrimer ions was pulsed on while the second quadrupole $(\mathrm{Q} 1)$, operated in mass resolving mode, was used to isolate and transmit the DAB charge state of interest into the third quadrupole (Q2) where the ions were trapped and cooled. The DAB dendrimer ions were cooled in Q2 at a pressure of 6 to $8 \mathrm{mTorr}$ of nitrogen, for $50 \mathrm{~ms}$, during which time the high voltage on the first emitter was turned off. After the cooling step, the power supply connected to the second nanoESI emitter, which was operated in the negative polarity, was triggered on to generate negative peptide ions, which were isolated by Q1 in mass resolving mode while being transmitted into the Q2 collision cell. The dc potentials applied to the ion path before Q2 were adjusted to allow ions of the opposite polarity to enter $\mathrm{Q} 2$. The positive DAB dendrimer ions and the negative peptide ions were stored together in Q2 for $500 \mathrm{~ms}$. The frequency of the auxiliary rf signal applied to the end lenses was optimized for the ion/ion reaction experiments to be $500 \mathrm{kHz}$ applied at a fixed voltage of 350 $\mathrm{mV}_{p-p}$. After the mutual storage time, any remaining analyte anions were removed by applying an attractive dc potential on the Q2 containment lenses while the auxiliary rf signals were terminated, and trapping dc potentials were applied to trap the residual DAB cations and charge inverted peptide ions inside the Q2 cell. In 
the final step, the product ions from the ion/ion charge inversion reaction were transferred into Q3 $\left(4.6 \times 10^{-5}\right.$ Torr) for mass analysis. The ions in Q3 were subjected to mass-selective axial ejection $[27,28]$ using a supplementary rf signal at a frequency of $310 \mathrm{kHz}$ to eject the ions from the Q3 cell. The spectra shown are typically the averages of 20 individual scans.

\section{Results and Discussion}

An ion/ion charge inversion experiment using a DAB dendrimer cation as the reagent is illustrated by the spectra of Figure 1. Specifically, the spectra illustrate the reaction of deprotonated YGGFLR with the 7+ ion of the generation $4 \mathrm{DAB}$ dendrimer $\left(\left[\mathrm{DAB}_{4}+\right.\right.$ $7 \mathrm{H}]^{7+}$ ). The product ion spectrum (panel c) shows protonated YGGFLR, residual $\left[\mathrm{DAB}_{4}+7 \mathrm{H}\right]^{7+}$ reactant cations, and various charge-reduced reactant cations, the most abundant of which is the $\left[\mathrm{DAB}_{4}+5 \mathrm{H}\right]^{5+}$ ion. This product is expected to be largely produced via a single ion/ion encounter that results in the transfer of two protons from the reactant cation to deprotonated YGGFLR. The transfer of two protons in a single ion/ion encounter is expected to proceed via a relatively long-lived intermediate but no evidence for a stabilized complex is apparent in Figure 1. This observation is consistent with all previous studies involving reactions of $\mathrm{DAB}$ dendrimer cations with polypeptide anions. However, the formation of adduct ions upon charge inversion has been noted with reagents, such as multiply protonated polypeptides, that interact strongly with the analyte in the long-lived intermediate.

The peptide YGGFLR contains one basic amino acid, arginine, and all other polypeptide ions demonstrated to undergo ion/ion charge inversion have also contained at least one basic amino acid (i.e., lysine, arginine, or histidine), in addition to the N-terminus. However, small polypeptide ions that lack a basic amino

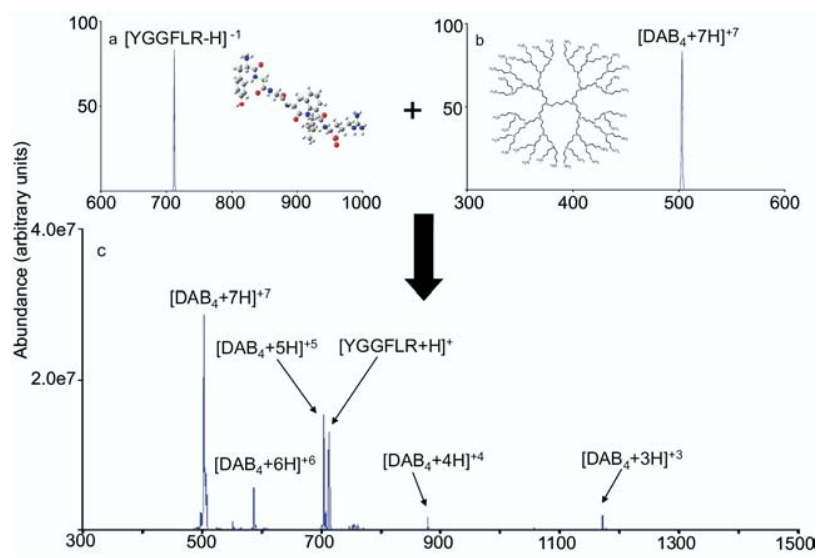

Figure 1. Summary of a negative to positive ion/ion reaction charge inversion experiment. (a) Isolated singly deprotonated YGGFLR; (b) Isolated $\left[\mathrm{DAB}_{4}+7 \mathrm{H}\right]^{7+}$ reagent; (c) Positive product ion spectrum from the reaction of singly deprotonated YGGFLR with $\left[\mathrm{DAB}_{4}+7 \mathrm{H}\right]^{7+}$. acid residue have been noted to show a significantly greater tendency to form adduct ions with DAB dendrimer charge inversion reagents, as illustrated in the data of Figure 2. Figure 2a shows the product ion spectrum from the reaction of deprotonated YGGFLF with $\left[\mathrm{DAB}_{5}+9 \mathrm{H}\right]^{9+}$ while Figure $2 \mathrm{~b}$ shows the product ion spectrum for the reaction of deprotonated YGGFLH with the same reagent cation. The predominant product ion from a single ion/ion reaction encounter involving deprotonated YGGFLF is a complex of YGGFLF with the $\mathrm{DAB}$ dendrimer to form the primary reaction product $\left[\mathrm{DAB}_{5}+\mathrm{YGGFLF}^{8+}\right.$. Ion/ion reaction products produced via multiple reactive collisions (i.e., from subsequent ion/ion reactions) are also noted including a product with four YGGFLF ions complexed with one $\mathrm{DAB}$ dendrimer ion to give $\left[\mathrm{DAB}_{5}+4 \mathrm{YGGFLF}\right]^{5+}$. The spectrum also contains a small signal for protonated YGGFLF as well as a small signal from the transfer of a single proton, which neutralizes the peptide and leads to $\left[\mathrm{DAB}_{5}+8 \mathrm{H}\right]^{8+}$. Single proton transfer in this case can occur via the formation of a long-lived complex with loss of a neutral peptide or via a "hopping" mechanism [29]. Small signals from products that may arise from subsequent reactions involving the $\left[\mathrm{DAB}_{5}+\right.$ $8 \mathrm{H}]^{8+}$ product, such as the $\left[\mathrm{DAB}_{5}+\mathrm{YGGFLF}^{7+}\right.$ ion, also appear in Figure 2a. The reaction of deprotonated YGGFLH, on the other hand, shows both charge inversion by double proton transfer to yield protonated YGGFLH as well as adduct formation. However, adduct formation is the minor process with this peptide.

The comparison of Figure $2 \mathrm{a}$ and $2 \mathrm{~b}$ strongly suggests that the composition of a peptide ion can play a significant role in the tendency for charge inversion via adduct formation or via multiple proton transfer. To examine factors underlying this observation, several singly deprotonated peptides with and without basic residues were subjected to ion/ion reactions with multiply protonated $\mathrm{DAB}$ dendrimer ions derived from generations 4 and 5 , specifically $\left[\mathrm{DAB}_{4}+7 \mathrm{H}\right]^{7+}$ and $\left[\mathrm{DAB}_{5}+9 \mathrm{H}\right]^{9+}$. The peptides studied were YGGFL, YGGFLF, YGGFLK, YGGFLR, YGGFLH, YGGHFL, and YGGKFL. Anions derived from the latter two peptides were examined to determine if the location of the basic residue is a factor in determining the extent of adduct formation upon charge inversion with the DAB cations. Comparisons of the behaviors of deprotonated YGGFLH and YGGHFL and deprotonated YGGKFL and YGGFLK indicated that the location of the basic residue is not an important factor in the reactivities of these model peptides (i.e., the isomeric peptide ions showed essentially identical charge inversion behavior [data not shown]).

Figure 3 summarizes the charge inversion results of five of the model peptides tested and gives the percentage charge inversion by proton transfer (open columns) and percentage complex formation (filled columns) of all the peptides. Percent charge inversion by proton transfer was calculated by dividing the abundance of the charge inverted peptide by the sum of the abun- 


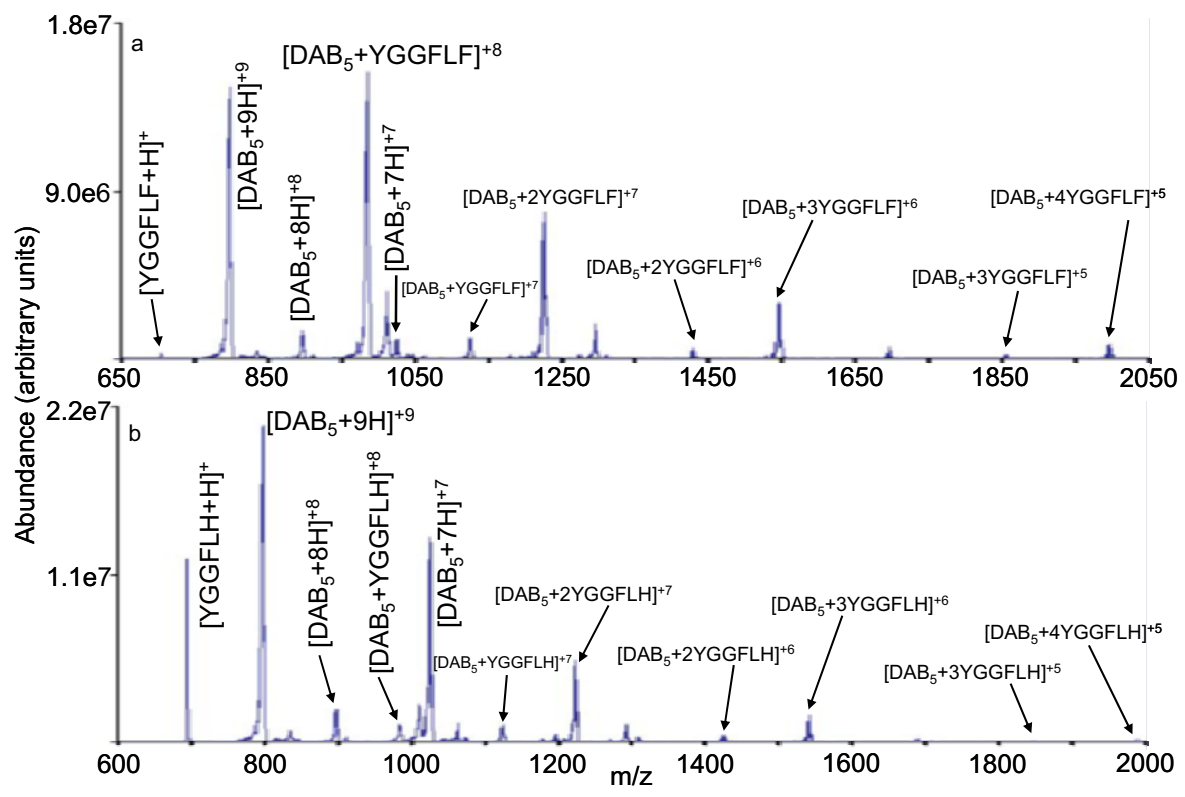

Figure 2. (a) Positive product ion spectrum from the reaction of singly deprotonated YGGFLF with $\left[\mathrm{DAB}_{5}+9 \mathrm{H}\right]^{9+}$; (b) Positive product ion spectrum from the reaction of singly deprotonated YGGFLH with $\left[\mathrm{DAB}_{5}+9 \mathrm{H}\right]^{9+}$.

dances of the charge inverted peptide and all the complexes formed between the peptide and dendrimer. Additionally, percent charge inversion by complex formation was calculated by dividing the total abundance of the dendrimer/peptide complexes by the sum of the abundances of the charge inverted peptide and all the dendrimer/peptide complexes. The peptides with no basic amino acid show almost exclusive adduct formation for both reagent ions. Note that collision-induced dissociation of the adduct species in all cases showed dissociation to the protonated peptide and the complementary DAB ion, which supports the conclusion that the adduct species is a stabilized intermediate in the

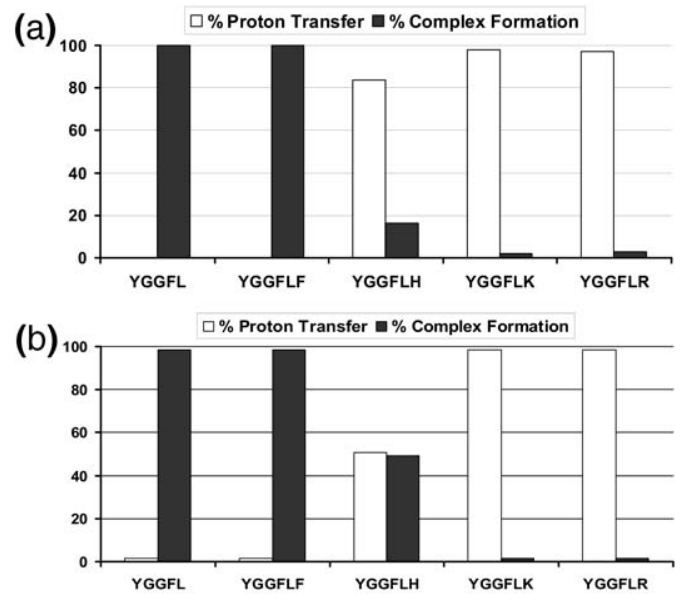

Figure 3. (a) Percent charge inversion of five model peptides by proton transfer or by complex formation with DAB generation 4 dendrimer +7 . (b) Percent charge inversion of five model peptides by proton transfer or by complex formation with DAB generation 5 dendrimer +9 . proton transfer process. The peptides with a lysine or arginine residue react predominantly via double proton transfer (i.e., very little adduct formation is observed). Deprotonated YGGFLH is the only analyte that gives substantial percentages of charge inversion by both proton transfer and complex formation. When reacted with the $\left[\mathrm{DAB}_{5}+9 \mathrm{H}\right]^{9+}$ ion, for example, YGGFLH was charge inverted by $\sim 52 \%$ proton transfer and $\sim 48 \%$ complex formation (see Figure $3 b$ ), showing somewhat less charge inversion by proton transfer than with the $\left[\mathrm{DAB}_{4}+7 \mathrm{H}\right]^{7+}$ ion (see Figure 3a). The overall trend is consistent with the proton affinities of the side chains in the peptides. Those of YGGFL and YGGFLF are much less basic than histidine, lysine, or arginine. For example, at $220.9 \mathrm{kcal} / \mathrm{mol}$, tyrosine has the highest proton affinity of all of the amino acids in YGGFL and YGGFLF whereas the proton affinities of histidine, lysine, and arginine are $231.5 \mathrm{kcal} / \mathrm{mol}, 235.6 \mathrm{kcal} / \mathrm{mol}$, and 244.8 $\mathrm{kcal} / \mathrm{mol}$, respectively [30]. There is some variation in reported amino acid proton affinities but the order indicated by these numbers is consistent with most listings [31]. The difference in the partitioning of the products for deprotonated YGGFLH using $\left[\mathrm{DAB}_{5}+\right.$ $9 \mathrm{H}]^{9+}$ versus $\left[\mathrm{DAB}_{4}+7 \mathrm{H}\right]^{7+}$ as reagents is consistent with a greater degree of electrostatic repulsion in the intermediate comprised of $\left[\mathrm{DAB}_{4}+7 \mathrm{H}\right]^{7+}(\mathrm{m} / \mathrm{z}=503)$ (i.e., $\left[\mathrm{DAB}_{4}+\mathrm{YGGFLH}+6 \mathrm{H}\right]^{6+}$ ) than that comprised of $\left[\mathrm{DAB}_{5}+9 \mathrm{H}\right]^{9+}(\mathrm{m} / \mathrm{z}=797)$ (i.e., $\left[\mathrm{DAB}_{5}+\mathrm{YGGFLH}+\right.$ $\left.8 \mathrm{H}]^{8+}\right)$. Although the absolute charge is greater in the latter case, the smaller volume of the $\mathrm{DAB}_{4}$ species is expected to more than compensate for the lower charge. Charge inversion via multiple proton transfer is favored at higher electrostatic fields because repulsion is minimized by the separation of products of 
like charge. Hence, the lesser degree of adduct formation with the $\left[\mathrm{DAB}_{4}+7 \mathrm{H}\right]^{7+}$ reagent is consistent with this picture.

\section{Modified Model Peptide Studies: Methyl Esterification and Acetylation}

To investigate the nature of the interactions within the intermediate, the peptides YGGFL, YGGFLF, YGGFLK, YGGFLR, and YGGFLH were modified by C-terminal methyl esterification or by $\mathrm{N}$-terminal acetylation, or both. In all cases, the $\left[\mathrm{DAB}_{4}+7 \mathrm{H}\right]^{7+}$ reagent was used to assess charge inversion reactivity. The methyl esterification of the C-terminus was performed to determine the possible role of the carboxylate group in determining the kinetic stability of the intermediate complex (i.e., its role in determining the likelihood for adduct formation). Methyl esterification of YGGFLF, for example, resulted in charge inversion of the deprotonated peptides predominantly by proton transfer $(86 \%)$ instead of by complex formation (14\%), in contrast with the unmodified species, which reacted essentially $100 \%$ by complex formation. Methyl esterification had no effect on charge inversion of either YGGFLK or YGGFLR in that double proton transfer was the dominant channel for both modified and unmodified forms. Methyl esterification of the YGGFLH anion resulted in essentially all charge inversion proceeding via double proton transfer (i.e., the complex formation channel also noted for the unmodified anion was essentially absent in the methyl esterified species).

The methyl esterification results clearly suggest that the C-terminal carboxylate group plays a role in the observation of adducts ions in the charge inversion of deprotonated YGGFL and YGGFLF. Two likely sites of interaction between the protonated amine group of the dendrimer and the peptide are the C-terminus of the peptide and the basic site(s) of the peptide, such as the N-terminus. Density functional theory (DFT) calculations were performed using Gaussian 03 [32] to determine the relative strengths of the interactions of protonated methylamine, which serves as a model for the protonated amine group of the dendrimer, with the carboxylate group and with the $\mathrm{NH}_{2}$ terminus of the model peptide glycine. The interaction between protonated methylamine and the $\mathrm{N}$-terminus of the peptide gives rise to a proton bound dimer, as shown in the top structure of Figure 4, whereas the interaction between the $\mathrm{COO}^{-}$group on the peptide's C-terminus and the dendrimer allows for the formation of a hydrogen bonded six-membered ring structure, as indicated in the bottom structure of Figure 4 . Density functional theory optimization calculations at the ub3lyp/6-31g $(+), d, p$ level show that the hydrogen bonded six membered ring formed between the C-terminus of the peptide and the protonated amine terminal group of the dendrimer is $\sim 6$ $\mathrm{kcal} / \mathrm{mol}$ more stable than the proton bound dimer between the dendrimer and peptide's N-terminus. This result is consistent with the experimental data, which (a)

Proton-bound dimer of methylamine and the $\mathrm{N}$-terminus of glycine

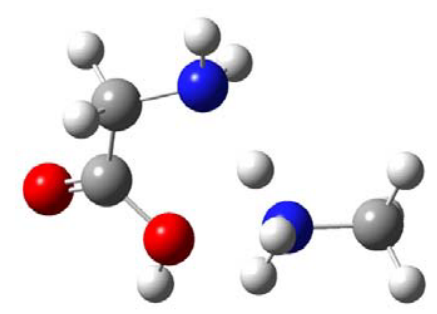

(b)

Six membered hydrogen bonded ring between the glycine carboxylate and $\mathrm{NH}_{3}{ }^{+}$of dendrimer

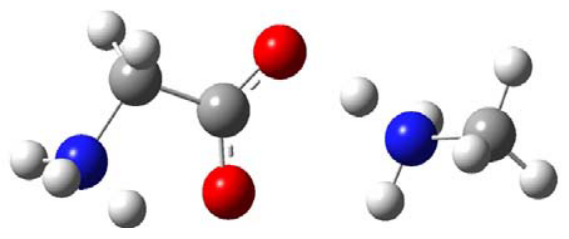

Figure 4. (a) Model interaction of dendrimer $\mathrm{NH}_{3}{ }^{+}$terminal group with the peptide $\mathrm{N}$-terminus from DFT calculations. (b) Model interaction of the dendrimer $\mathrm{NH}_{3}{ }^{+}$terminal group with the C-terminal carboxylate of a peptide.

suggests that the C-terminal carboxylate of the peptide is important for stable complex formation between the peptide and dendrimer.

Modification of primary amine groups of the peptides YGGFLF and YGGFLR gave rise to no observable change in the charge inversion reactivity, whereas differences were noted for modified YGGFLK and YGGFLH. A single acetylation of YGGFLK is likely to lead to a mixture of structures with acetylation at either the $\mathrm{N}$-terminus or the $\varepsilon$-amine of lysine. The anion of singly acetylated YGGFLK showed $84 \%$ proton transfer and $16 \%$ complex formation, which contrasts with the $100 \%$ proton transfer noted for the unmodified peptide. When both the $\mathrm{N}$-terminus and the $\varepsilon$-amine of the lysine side chain were acetylated in this peptide, which converted both of the basic sites of the peptide to less basic amides, the deprotonated species reacted $100 \%$ by complex formation. Acetylation of the YGGFLH anion altered the partitioning of products from $82 \%$ proton transfer in the unmodified form to $31 \%$ proton transfer in the modified form. The N-terminal acetylated YGGFLF anion charge inverted $100 \%$ by complex formation just as the unmodified form of the peptide did. The N-terminal acetylated YGGFLR anion charge inverted $100 \%$ by proton transfer, in direct analogy to its unmodified counterpart.

Methyl esterification of the peptides highlighted the importance of the C-terminus in adduct ion formation, presumably due to its relatively strong interaction with the dendrimer amine groups, and primary amine acetylation of YGGFLK confirmed the importance of having a relatively strong basic site for double proton transfer. The two modifications tend to work at cross purposes (see below). Peptides YGGFL, YGGFLK, and YGGFLH were subjected to both primary amine acetylation and C-terminal methyl esterification to determine the effect 
of both removing the C-terminus and reducing the peptide basicity. The doubly modified YGGFL anion charge inverted $100 \%$ by complex formation, in analogy with the unmodified YGGFL anion.

Triply modified YGGFLK (in which both the Nterminus and the lysine side-chain amine were acetylated and the C-terminus was methyl esterified) charge inverted by $100 \%$ complex formation, unlike the unmodified version of the anion, which reacted $100 \%$ by double proton transfer, but like the doubly acetylated version of the anion. As with the doubly modified YGGFL anion, methyl esterification may reduce the thermodynamic stability of the complex but the reduction of the basicity of the peptide by acetylation apparently increases the kinetic stability of the complex to the extent that it more than compensates for the reduction in thermodynamic stability. Doubly modified YGGFLH, whose side chain cannot be acetylated, charge inverted mainly by proton transfer $(75 \%)$. This result is consistent with the behavior of the other forms of YGGFLH in that methyl esterification alone increases proton transfer, acetylation alone reduces proton transfer, and both modifications present simultaneously leads to an intermediate degree of proton transfer.

The results reported here all appear to be consistent with the relative contribution of adduct formation to the ion/ion charge inversion production spectrum being related to the lifetime of the long-lived intermediate and that the chemical composition of the peptide can play a significant role in determining the lifetime. The various observations can be put into context by reference to the generalized energy diagram of Figure 5, which shows potential energy as reactants proceed through the intermediate and on to products from left to right for the case of a singly deprotonated molecule, $\mathrm{M}$, in reaction with a multiply protonated DAB dendrimer, (DAB + $\mathrm{nH})^{n+}$. Specifically, the diagram represents the case for the net conversion of $(\mathrm{M}-\mathrm{H})^{-}$to $(\mathrm{M}+\mathrm{H})^{+}$and with the reagent ion retaining a positive charge such that the exit channel shows a so-called Coulomb barrier. This case applies to the experiments described herein. The likelihood that the long-lived intermediate separates to

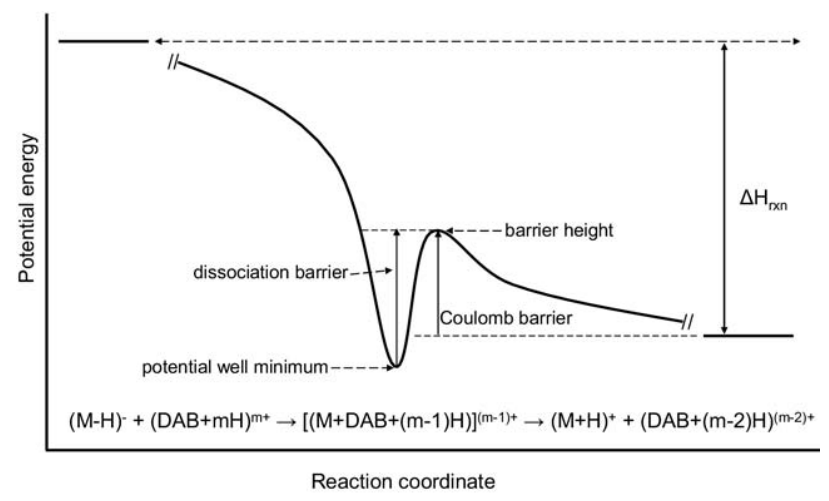

Figure 5. Generalized energy diagram for the reaction of a deprotonated peptide, $(\mathrm{M}-\mathrm{H})^{-}$, with a multiply protonated DAB dendrimer reagent ion to yield the protonated peptide, $(\mathrm{M}+\mathrm{H})^{+}$. products or is stabilized by emission or collisions is dependent upon a number of factors, which include the overall heat of reaction, $\Delta \mathrm{H}_{\mathrm{rxn}}$, the number of degrees of freedom of the reactants, reaction conditions (such as pressure and reactant relative velocity), reactant charge states and sizes, etc. In the cases described here, for a given reagent cation, the reaction conditions, contribution to the energy surface due to charges of the ions, and numbers of degrees of freedom are very similar for each of the model peptide experiments. The major difference between the various model peptides is likely to be the magnitude of the dissociation barrier. In this work, the magnitude of this barrier could be affected by methyl esterifying the C-terminus, which mostly affects the position of the minimum of the potential well of the intermediate by eliminating the possibility for the relatively strong interaction between the carboxylate of the peptide and a protonated amine of the dendrimer, and varying the proton affinity of the analyte ion, the major effect of which is to alter the position of the height of barrier to products. All else being equal, increasing the proton affinity has the effect of reducing the barrier height. The dissociation barrier is the difference between the barrier height and the minimum of the potential well.

All of the unmodified model peptides can form the relatively strong interaction between the C-terminal carboxylate group and the protonated amine of the dendrimer. However, YGGFLH, YGGFLK, and YGGFLR are significantly more basic than either YGGFL or YGGFLF because the former have two basic sites (i.e., the sidechain of the basic residue and the N-terminus) whereas the N-terminus is the only basic site in the latter two peptides. Hence, the barrier height for the nonbasic peptides is likely to be higher than for the basic peptides. Hence, the peptides with a lower basicity tend to show more adduct formation. Methyl esterification reduces the dissociation barrier for all peptides by increasing the minimum of the well-depth and, as a result, all methyl esterified anions that are not acetylated show little adduct formation. Acetylation of a primary amine significantly reduces the basicity of the modified site. This modification affected the charge inversion behaviors of the anions of YGGFLH and singly-acetylated YGGFLK modestly, and that of the doubly-acetylated anion of YGGFLK dramatically. In the former cases, acetylation impacted only one of the basic sites whereas in the latter case both basic sites were modified. As a result, in the case of the YGGFLK anion, the doubly-acetylated form of the peptide anion reacted predominantly via adduct formation. The reactivity of the anion of the nonbasic peptide YGGFLF was unchanged upon modification because it reacted by adduct formation even before modification. Reducing the basicity of the $\mathrm{N}$-terminus would be expected to stabilize the complex even further. The basicity of YGGFLR was apparently insufficiently reduced by acetylation of the N-terminus to result in any adduct formation but an increase in adduct formation was 
clearly apparent from acetylation of the N-terminus YGGFLH.

Methyl esterification and acetylation tend to have opposing effects on the lifetime of the intermediate. In the cases of YGGFL, acetylation of the N-terminus apparently more than compensates for methyl esterification of the C-terminus such that adduct formation dominates. This is also the case with methyl esterified YGGFLK with both primary amine groups being acetylated. Acetylated and methyl esterified YGGFLH, on the other hand, reacts predominantly via double proton transfer. Acetylation of the N-terminus of this peptide has little effect on its charge inversion behavior, relative to the methyl esterified-only version, because the histidine side chain is unaffected by the acetylation. The barrier height is therefore minimally affected in this case.

\section{Conclusions}

The composition of a peptide anion can play a significant role in its charge inversion resulting from an ion/ion reaction with a multiply-protonated DAB dendrimer. Charge inversion can occur either by multiple proton transfers via a long-lived complex intermediate or via adduct formation resulting from stabilization of the intermediate. Two particularly important compositional characteristics of the peptide ion have been found to influence the extent to which the stabilized intermediate is observed. First, the C-terminus can engage in a relatively strong interaction with a protonated amine group of the dendrimer, thereby increasing the stability of the long-lived collision complex. Second, the basicity of the peptide plays a role in determining the barrier height for dissociation of the complex to yield proton transfer products. When a basic amino acid is present in the peptide, charge inversion via multiple proton transfers tends to be the dominant process for the relatively small model peptides examined here.

A number of factors can potentially play a role in the extent to which adduct formation is observed in an ion/ion charge inversion reaction. These include, for example, the composition and charge state of the reagent ion and the reaction conditions. The use of conditions that would give rise to mild collisional activation of the ion/ ion reaction products, for example, would tend to dissociate any complexes and thereby mask the effects noted here. This work highlights the first example of the role that the chemical composition of a peptide analyte can play in determining the extent to which attachment can occur in an ion/ion charge inversion reaction. The results hint at the possibility of the use of ion/ion charge inversion reactions to screen for chemical functionalities in analyte species on the basis of ion/ion attachment versus multiple proton transfers.

\section{Acknowledgments}

The authors acknowledge Dr. John Nash and Mr. Alex Davis for helpful advice in performing the DFT calculations and evaluating the results. They acknowledge support for this work by the Office of Basic Energy Sciences, Division of Chemical Sciences under award no. DE-FG02-00ER15105.

\section{References}

1. He, M.; McLuckey, S. A. Two Ion/ion Charge Inversion Steps to form a Doubly-protonated Peptide from a Singly-protonated Peptide in the Gas Phase. J. Am. Chem. Soc. 2003, 125, 7756-7757.

2. He, M.; McLuckey, S. A. Increasing the Negative Charge of a MacroAnion in the Gas Phase via Sequential Charge Inversion Reactions. Anal. Chem. 2004, 76, 4189-4192.

3. He, M.; Emory, J. F.; McLuckey, S. A. Reagent Anions for Charge Inversion of Polypeptide/Protein Cations in the Gas Phase. Anal. Chem. 2005, 77, 3173-3182.

4. He, M.; McLuckey, S. A. Charge Permutation Reactions in Tandem Mass Spectrometry. J. Mass Spectrom. 2004, 39, 1231-1259.

5. Danell, A. S.; Glish, G. L. Charge Permutation Reactions in Beam Type Mass Spectrometers. Int. J. Mass Spectrom. 2001, 212, 219-227.

6. Bowie, J. H.; Blumenthal, T. The +E Collision Induced Mass Spectra from Negative Ions. J. Am. Chem. Soc. 1975, 97, 2959-2962.

7. Hayakawa, S. Internal Energy Distribution in Charge Inversion Mass Spectrometry Using Alkali Metal Targets. Int. J. Mass Spectrom. 2001, 212, 229-247.

8. Fenn, J. B.; Mann, M.; Meng, C. K.; Wong, S. F.; Whitehouse, C. M. Electrospray Ionization for Mass Spectrometry of Large Biomolecules. Science 1989, 246, 64-71.

9. Muddiman, D. C.; Cheng, X. H.; Udseth, H. R.; Smith, R. D. ChargeState Reduction with Improved Signal Intensity of Oligonucleotides in Electrospray Ionization Mass Spectrometry. J. Am. Soc. Mass Spectrom. 1996, 7, 697-706.

10. McLuckey, S. A.; Van Berkel, G. J.; Glish, G. L. Reactions of Dimethylamine with Multiply Charged Ions of Cytochrome. c. J. Am. Chem. Soc. 1990, 112, 5668-5670

11. McLuckey, S. A.; Glish, G. L.; Van Berkel, G. J. Charge Determination of Product Ions Formed from Collision-Induced Dissociation of Multiply Protonated Molecules Via Ion/Molecule Reactions. Anal. Chem. 1991, 63, 1971-1978.

12. Williams, E. R. Proton Transfer Reactivity of Large Multiply Charged Ions. J. Mass Spectrom. 1996, 31, 831-842.

13. Shelimov, K. G.; Jarrold, M. J. Conformations, Unfolding, and Refolding of Apomyoglobin in Vacuum: An Activation Barrier for Gas-Phase Protein Folding. J. Am. Chem. Soc. 1997, 119, 2987-2994.

14. Loo, R. R. O.; Udseth, H. R.; Smith, R. D. Evidence of Charge Inversion in the Reaction of Singly-Charged Anions with Multiply-Charged Macro-Ions. J. Phys. Chem. 1991, 95, 6412-6415.

15. Loo, R. R. O.; Smith, R. D. Proton Transfer Reactions of Multiply Charged Peptide and Protein Cations and Anions. J. Mass Spectrom. 1995, 30, 339-347.

16. Herron, W. J.; Goeringer, D. E.; McLuckey, S. A. Ion/Ion Reactions in the Gas Phase: Proton Transfer Reactions of Protonated Pyridine with Multiply-Charged Oligonucleotide Anions. J. Am. Soc. Mass Spectrom. $1995,6,529-532$

17. Stephenson, J. L. Jr.; McLuckey, S. A. Ion/Ion Reactions in the Gas Phase: Proton Transfer Reactions Involving Multiply-Charged Proteins. J. Am. Chem. Soc. 1996, 118, 7390-7397.

18. Scalf, M.; Westphall, M. S.; Krause, J.; Kaufman, S. L.; Smith, L. M. Controlling Charge States of Large Ions. Science 1999, 283, 194-197.

19. Ebeling, D. D.; Westphall, M. S.; Scalf, M.; Smith, L. M. Charge Reduction Electrospray Mass Spectrometry. Anal. Chem. 2000, 72, 5158 5161.

20. McLuckey, S. A.; Stephenson, J. L. Jr.; Asano, K. G. Ion/ion Proton Transfer Kinetics: Implications for Analysis of Ions Derived from Electrospray of Protein Mixtures. Anal. Chem. 1998, 70, 1198-1202.

21. Stephenson, J. L. Jr.; McLuckey, S. A. Ion/ion Reactions for Oligopeptide Mixture Analysis: Application to Mixtures Comprised of 0.5 to 100 kDa Components. I. Am. Soc. Mass Spectrom. 1998, 9, 585-596.

22. McLuckey, S. A.; Reid, G. E.; Wells, J. M. Anal. Chem. 2002, 74, 336-346

23. Schaaff, T. G.; Cargile, B. J.; Stephenson, J. L.; McLuckey, S. A. Anal. Chem. 2000, 72, 899-907.

24. Wells, J. M.; Stephenson, J. L.; McLuckey, S. A. Int. J. Mass Spectrom. 2000, 203, A1-A9.

25. Emory, J. F.; McLuckey, S. A. Charge Inversion of Polypeptide Anions Using Protein and Dendrimer Cations as Charge Inversion Reagents. Int. J. Mass Spectrom. 2008, in press.

26. Liang, X.; Han, H.; Xia, Y.; McLuckey, S. A. A Pulsed Triple Ionization Source for Sequential Ion/Ion Reactions in an Electrodynamic Ion Trap. J. Am. Soc. Mass Spectrom. 2007, 18, 369-376.

27. Hager, J. W. A New Linear Ion Trap Mass Spectrometer. Rapid Commun. Mass Spectrom. 2002, 16, 512-526.

28. Londry, F. A.; Hager, J. W. Mass Selective Axial Ejection from a Linear Quadrupole Ion Trap. J. Am. Soc. Mass Spectrom. 2003, 14, 1130-1147.

29. Wells, J. M.; Chrisman, P. A.; McLuckey, S. A. Formation and Characterization of Protein-Protein Complexes in Vacuo. J. Am. Chem. Soc. 2003, 125, 7238-7249

30. Harrison, A. G. The Gas-Phase Basicities and Proton Affinities of Amino Acids and Peptides. Mass Spectrom. Rev. 1997, 16, 201-217. 
31. Bleiholder, C.; Suhai, S.; Paizs, B. Revising the Proton Affinity Scale of the Naturally Occurring $\alpha$-Amino Acids. J. Am. Soc. Mass Spectrom. 2006, $17,1275-1281$.

32. Frisch, M. J.; Trucks, G. W.; Schlegel, H. B.; Scuseria, G. E.; Robb, M. A.; Cheeseman, J. R.; Montgomery, J. J. A.; Vreven, T.; Kudin, K. N.; Burant, J. C.; Millam, J. M.; Iyengar, S. S.; Tomasi, J.; Barone, V.; Mennucci, B.; Cossi, M.; Scalmani, G.; Rega, N.; Petersson, G. A.; Nakatsuji, H.; Hada, M.; Ehara, M.; Toyota, K.; Fukuda, R.; Hasegawa, J.; Ishida, M.; Nakajima, T.; Honda, Y.; Kitao, O.; Nakai, H.; Klene, M.; Li, X.; Knox, J. E.; Hratchian, H. P.; Cross, J. B.; Adamo, C.;
Jaramillo, J.; Gomperts, R.; Stratmann, R. E.; Yazyev, O.; Austin, A. J.; Cammi, R.; Pomelli, C.; Ochterski, J. W.; Ayala, P. Y.; Morokuma, K.; Voth, G. A.; Salvador, P.; Dannenberg, J. J.; Zakrzewski, V. G.; Dapprich, S.; Daniels, A. D.; Strain, M. C.; Farkas, O.; Malick, D. K.; Rabuck, A. D.; Raghavachari, K.; Foresman, J. B.; Ortiz, J. V.; Cui, Q.; Baboul, A. G.; Clifford, S.; Cioslowski, J.; Stefanov, B. B.; Liu, G.; Liashenko, A.; Piskorz, P.; Komaromi, I.; Martin, R. L.; Fox, D. J.; Keith, T.; Al-Laham, M. A.; Peng, C. Y.; Nanayakkara, A.; Challacombe, M.; Gill, P. M. W.; Johnson, B.; Chen, W.; Wong, M. W.; Gonzalez, C.; Pople, J. A. Gaussian 03; Gaussian, Inc.: Pittsburgh PA, 2003. 